\title{
Matrine inhibits the adhesion and migration of BCG823 gastric cancer cells by affecting the structure and function of the vasodilator-stimulated phosphoprotein (VASP)
}

\author{
Jing-wei ZHANG ${ }^{1, \#}, \mathrm{Ke} \mathrm{SU}^{2, \#}$, Wen-tao $\mathrm{SHI}^{2, \#}$, Ying WANG ${ }^{2}$, Peng-chao $\mathrm{HU}^{2}$, Yang WANG ${ }^{2}$, Lei WEI ${ }^{2}$, Jin XIANG ${ }^{3, *}$, Fang \\ $\mathrm{YANG}^{2, *}$
}

\begin{abstract}
${ }^{1}$ Department of Oncology, Zhongnan Hospital of Wuhan University, Hubei Key Laboratory of Tumor Biological Behaviors, Hubei Cancer Clinical Study Center, Wuhan 430071, China; ${ }^{2}$ Department of Pathophysiology, School of Medicine, Wuhan University, Wuhan 430071, China; ${ }^{3}$ Ministry of Education Laboratory of Combinatorial Biosynthesis and Drug Discovery, School of Pharmaceutical Science, Wuhan University, Wuhan 430071, China
\end{abstract}

\begin{abstract}
Aim: Vasodilator-stimulated phosphoprotein (VASP) expression is upregulated in human cancers and correlates with more invasive advanced tumor stages. The aim of this study was to elucidate the mechanisms by which matrine, an alkaloid derived from Sophora species plants, acted on the VASP protein in human gastric cancer cells in vitro.

Methods: VASP was expressed and purified. Intrinsic fluorescence spectroscopy was used to study the binding of matrine to VASP. CD spectroscopy was used to examine the changes in the VASP protein secondary structure. Human gastric carcinoma cell line BGC823 was tested. Scratch wound and cell adhesion assays were used to detect the cell migration and adhesion, respectively. Real-time PCR and Western blotting assays were used to measure mRNA and protein expression of VASP.

Results: In the fluorescence assay, the dissociation constant for binding of matrine to VASP protein was $0.86 \mathrm{mmol} / \mathrm{L}$, thus the direct binding between the two molecules was weak. However, matrine $(50 \mu \mathrm{g} / \mathrm{mL})$ caused obvious change in the secondary structure of VASP protein shown in CD spectrum. Treatments of BGC823 cells with matrine $(50 \mu \mathrm{g} / \mathrm{mL})$ significantly inhibited the cell migration and adhesion. The alkaloid changed the subcellular distribution of VASP and formation of actin stress fibers in BGC823 cells. The alkaloid caused small but statistically significant decreases in VASP protein expression and phosphorylation, but had no significant effect on VASP mRNA expression.

Conclusion: Matrine modulates the structure, subcellular distribution, expression and phosphorylation of VASP in human gastric cancer cells, thus inhibiting the cancer cell adhesion and migration.
\end{abstract}

Keywords: matrine; human gastric carcinoma; vasodilator-stimulated phosphoprotein (VASP); cell adhesion; cell migration; actin stress fiber; intrinsic fluorescence spectroscopy; circular dichroismmatrine

Acta Pharmacologica Sinica (2013) 34: 1084-1092; doi: 10.1038/aps.2013.15; published online 20 May 2013

\section{Introduction}

The occurrence of gastric cancer cases is rising rapidly. For patients with metastatic gastric cancer the survival rate is only $50 \%$. Matrine, a natural alkaloid component that is derived from Sophora species plants and has a long history of being used in traditional Chinese medicine to treat inflammatory

\footnotetext{
\# These authors contributed equally to this work.

* To whom correspondence should be addressed.

E-mail xiangjin@whu.edu.cn (Jin XIANG);

fang-yang@whu.edu.cn (Fang YANG)

Received 2012-11-12 Accepted 2013-02-07
}

diseases and solid cancers, including gastric, liver, colon, lung, ovary, and breast cancers, and has been used in combination with chemotherapy or radiotherapy to reduce toxicity to normal cells ${ }^{[1-3]}$. In vitro and in vivo studies have demonstrated that matrine can inhibit the growth of various human tumor cell lines by promoting apoptosis through the upregulation of Bax expression and the downregulation of growth factor receptors such as Akt and nuclear factor-kappa B (NF-kB), which are involved in the epidermal growth factor (EGF)/vascular endothelial growth factor (VEGF)-VEGFR1-Akt-NF-kB signaling pathway. Preliminary studies also showed that matrine could exhibit antitumor activities by interrupting cell- 
cell adhesion and migration, indicating that matrine could potentially prevent tumor invasion and metastasis ${ }^{[4-7]}$.

Cell migration requires a coordinated series of events, including cell adhesion to the extracellular matrix and membrane protrusion and retraction in space and time, to generate a productive and net forward movement that is dependent on the assembly, disassembly or reorganization of the actin cytoskeleton $^{[8]}$. The cytoskeleton protein vasodilator-stimulated phosphoprotein (VASP) is the initial member of the Enabled (Ena)/VASP family, the members of which are predominantly localized to the stress fibers, cell-matrix and cellcell adherent junctions, and highly dynamic membrane areas. It is now widely accepted that Ena/VASP proteins can influence the lengths of actin filaments as well as their apparent branching density within lamellipodia and that these proteins are required for the formation of filopodia ${ }^{[9,10]}$. VASP activity is primarily regulated by phosphorylation, and the phosphorylation of VASP has been shown to be crucial to the regulation of cell adhesion and migration. Although three common target phosphorylation sites of the cGMP-dependent protein kinase/cAMP-dependent protein kinase have been identified in human VASP (Ser157, Ser239, and Thr278), Ser-157 is the preferred target for PKA.

A number of studies have focused on the roles of Ena/ VASP proteins in tumor development and progression ${ }^{[11-15]}$. VASP protein expression is upregulated in human lung carcinomas and breast cancers and correlates with more invasive advanced tumor stages; therefore, the inhibition of VASP expression and activity might interfere with tumor growth, invasion and metastasis.

Matrine has been reported to inhibit human cancer cell migration, adhesion and proliferation by inhibiting the phosphorylation of VASP ${ }^{[6,8,16-18]}$. However, the precise mechanism by which matrine acts directly on VASP remains unknown. In this study, the effects of matrine on the structure, subcellular distribution, transcription, and expression of VASP were investigated to explore a possible mechanism for the inhibitory effects of matrine on human gastric cancer cells.

\section{Materials and methods} Chemicals and reagents

Matrine (Molecular weight: 248.364; No XHBZP-014) was purchased from Xi-an Xu-Huang Biotechnology Co, Ltd, China (Figure 1). The purity of this compound was greater than $98 \%$ as determined by HPLC analysis and reported by the supplier. Dulbecco's modified Eagle's medium (DMEM), fetal bovine

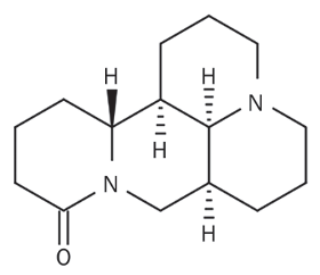

Figure 1. Chemical structures of matrine. serum (FBS), antibiotics, and trypsin were purchased from Gibco (Grand Island, NY, USA). Unless otherwise specified, all chemicals used in this study were purchased from Sigma (St Louis, MO, USA).

\section{Protein expression, purification, and analysis}

The full-length cDNA sequence of VASP was cloned into a pET-28a (+) vector. VASP was expressed in E coli Rosetta and was induced with $0.5 \mathrm{mmol} / \mathrm{L}$ isopropyl-1-thio- $\beta-D$ galactopyranoside (IPTG) at $18^{\circ} \mathrm{C}$ for $16 \mathrm{~h}$. According to the previously described purification method ${ }^{[19]}$, the bacteria were harvested by high-speed centrifugation for $15 \mathrm{~min}$ and lysed in $50 \mathrm{mmol} / \mathrm{L} \mathrm{NaH}_{2} \mathrm{PO}_{4}, 300 \mathrm{mmol} / \mathrm{L} \mathrm{NaCl}$ (pH 8.0), $10 \mathrm{mmol} / \mathrm{L}$ imidazole, $10 \mathrm{mmol} / \mathrm{L} \beta$-mercaptoethanol, $1 \mathrm{mmol} / \mathrm{L}$ PMSF and a Protease Inhibitor Cocktail (Roche). The supernatant was batch-bound to a Ni-NTA resin (QIAGEN). The resin was washed twice with increasing concentrations of imidazole (20 $\mathrm{mmol} / \mathrm{L}$ and $50 \mathrm{mmol} / \mathrm{L}$ ) and was subsequently eluted with an elution buffer that contained $500 \mathrm{mmol} / \mathrm{L}$ imidazole. Each fraction was analyzed by sodium dodecyl sulfate polyacrylamide gel electrophoresis (SDS-PAGE). A 2-3 mg amount of VASP was purified from $1 \mathrm{~L}$ of bacterial culture with this method. VASP stocks were stored in sodium phosphate buffer at $4^{\circ} \mathrm{C}$ until protein analysis during the following week.

\section{Intrinsic fluorescence spectroscopy}

The intrinsic fluorescence spectroscopic experiments to investigate the interaction of matrine with VASP were performed at $25.0^{\circ} \mathrm{C}$ on a LS-55 luminescence spectrometer (Perkin-Elmer Life Sciences, Shelton, CT, USA). An excitation wavelength of $295 \mathrm{~nm}$ was used for the intrinsic fluorescence measurements, and the emission spectra were recorded between 300 and 450 $\mathrm{nm}$. The excitation and emission slits were both $10 \mathrm{~nm}$, and the scan speed was $1000 \mathrm{~nm} / \mathrm{min}$. Six hundred microliters of VASP $(0.35 \mu \mathrm{mol} / \mathrm{L})$ were placed in a $1 \mathrm{~mm}$ thermostated quartz fluorescence cuvette and titrated with $9 \mathrm{mg} / \mathrm{mL}$ matrine with continuous stirring. The fluorescence measurements were performed on protein samples that had optical densities at $280 \mathrm{~nm}$ of less than 0.3 to avoid the inner filter effects ${ }^{[20]}$. The fluorescence of a control system, which consisted of buffer that was titrated with an equivalent amount of matrine, was also measured under the same conditions and the results were used to correct the observed fluorescence of the samples. Each spectrum was scanned three times to acquire the final fluorescence emission spectra. The plot was fitted to the following equation: $\Delta F / \Delta F_{\max }=[$ Matrine $] /\left([\right.$ Matrine $\left.]+K_{\mathrm{d}}\right) . \Delta F$ is the fluorescence intensity change after each injection. $\Delta F_{\max }$ is the maximum fluorescence intensity change. [Matrine] is the concentration of matrine.

\section{Circular dichroism (CD) spectroscopy}

The far-UV CD spectra were measured in the 190-250 nm wavelength region (protein secondary structure) at $25.0^{\circ} \mathrm{C}$ on a Jasco J-810 spectropolarimeter (Jasco Corporation, Tokyo, Japan) with a $0.1 \mathrm{~cm}$ path length cylindrical cell. The bandwidth was $1 \mathrm{~nm}$ and the response time was $1 \mathrm{~s}$. VASP was 
thoroughly mixed with different concentrations of matrine in a $\mathrm{NaH}_{2} \mathrm{PO}_{4}-\mathrm{Na}_{2} \mathrm{HPO}_{4}$ buffer (10 mmol/L, $\left.\mathrm{pH} 7.4\right)$ and allowed to equilibrate thermally for $4 \mathrm{~min}$ prior to the $\mathrm{CD}$ measurements. Each sample spectrum was corrected by subtraction from the spectrum (baseline) that was recorded for buffer mixed with an equivalent concentration of matrine. The relative change in the a-helical content of VASP, represented by the relative change in the molar ellipticity of VASP at $222 \mathrm{~nm}$, was calculated from the CD spectra ${ }^{[21]}$. Each spectrum is an average of three different scans that were obtained by collecting data at $0.1 \mathrm{~nm}$ intervals at a scan speed of $200 \mathrm{~nm} / \mathrm{min}$.

\section{Cell culture}

The human gastric carcinoma undifferentiated cell line BGC823 was obtained from the China Center for Type Culture Collection. The cells were maintained in complete DMEM that was supplemented with $10 \% \mathrm{FBS}$ at $37^{\circ} \mathrm{C}$ in an atmosphere of $5 \% \mathrm{CO}_{2}$.

\section{Scratch wound assay (two-dimensional cell migration assay)}

Cells were plated evenly at a density of $1 \times 10^{6}$ cells $/ \mathrm{mL}$ in a 6-well plate and allowed to grow to $100 \%$ confluence. The cells were serum starved for $12 \mathrm{~h}$ before a wound was scratched across the monolayer of cells on the inner bottom of each well with a P-200 pipette tip. The cells were washed twice with phosphate buffer saline (PBS) to remove the cell debris, and serum-free DMEM with $10 \mu \mathrm{g} / \mathrm{mL}$ of mitomycin C and different concentrations of matrine $(0,50$, and $100 \mu \mathrm{g} / \mathrm{mL})$ was added to each well. Cells within the same fields were photographed at 0 and $24 \mathrm{~h}$ after the cells were scratched. The percentage of wound closure was calculated according to the following formula, in which $\mathrm{S}$ is the surface area of the wound field:

Percentage of wound closure $=\left(\mathrm{S}_{0 \mathrm{~h}}-\mathrm{S}_{24 \mathrm{~h}}\right) / \mathrm{S}_{0 \mathrm{~h}} \times 100 \%$

\section{Cell adhesion assay}

The 96-well plates were coated with $50 \mu \mathrm{L}$ fibronectin (Fn; 20 $\mu \mathrm{g} / \mathrm{mL})$ or Matrigel $(200 \mu \mathrm{g} / \mathrm{mL}$; Becton-Dickinson, Heidelberg, Germany) at $37^{\circ} \mathrm{C}$ for $2 \mathrm{~h}$, washed twice with PBS and blocked with serum-free DMEM+2\% BSA for $30 \mathrm{~min}$ at $37^{\circ} \mathrm{C}$. BGC823 cells were treated with different concentrations of matrine $(0,50$, and $100 \mu \mathrm{g} / \mathrm{mL})$ for $24 \mathrm{~h}$ at $37^{\circ} \mathrm{C}$ in a humidified incubator supplemented with $5 \%$ carbon dioxide. The treated cells were subsequently harvested with $0.25 \%$ trypsinEDTA, resuspended to a density of $1 \times 10^{5}$ cells $/ \mathrm{mL}$ in serumfree DMEM medium and seeded into the previously coated 96-well plates at a volume of $100 \mu \mathrm{L}$ per well. The cells were allowed to adhere to the plates for $1.5 \mathrm{~h}$ at $37^{\circ} \mathrm{C}$.

After the cells were gently washed twice with PBS to remove the non-adherent cells, $20 \mu \mathrm{L}$ of 3-(4,5-dimethyl-2-thiazolyl)2,5-diphenyltetrazolium bromide (MTT) were added to each well. The MTT was removed after a $4 \mathrm{~h}$ incubation and $200 \mu \mathrm{L}$ of dimethylsulfoxide (DMSO) were added to each well. After $15 \mathrm{~min}$, the optical density (OD) at $570 \mathrm{~nm}$ of each well was measured with a microplate reader. The experiments were performed three times. Control cells were not treated with matrine. The cell adhesion ratio was calculated according to the following formula:

$$
\text { Cell adhesion ratio }=O D_{570 \text { treated group }} / O D_{570 \text { untreated group }} \times 100 \%
$$

\section{Immunofluorescence confocal imaging}

Cells were seeded onto sterilized coverslips and incubated with treatments as described in the figure legends. Subsequently, the cells were fixed in PBS $+4 \%$ formaldehyde for 10 min, permeabilized in PBS+0.2\% Triton X-100 for $10 \mathrm{~min}$, and blocked with PBS+5\% BSA for $30 \mathrm{~min}$. Cells were stained for VASP expression with a primary anti-total VASP (Alexis IE273) antibody (1:100 dilution) at $4{ }^{\circ} \mathrm{C}$ overnight and with a rhodamine-labeled secondary antibody (Jackson Immunoresearch, West Grove, PA, USA) for $1 \mathrm{~h}$ at room temperature. F-actin was stained with Alexa 488-Phalloidin (Invitrogen A12379, USA) for $40 \mathrm{~min}$ and cell nuclei were stained with Hoechst (Sigma Aldrich, USA). The coverslips were then mounted on slides with glycerol. The cells were visualized with a PE Ultra View VOX for fluorescence to detect the subcellular distribution of the actin cytoskeleton and VASP. The green fluorescence represents actin, the red fluorescence represents VASP, and the blue fluorescence represents the cell nucleus.

\section{Semi-quantitative real-time PCR}

Real-time PCR was used to perform a semi-quantitative analysis to examine the VASP expression levels after cells were exposed to matrine $(0,50$, and $100 \mu \mathrm{g} / \mathrm{mL})$ for $24 \mathrm{~h}$. Total RNA was extracted from cells with TRIzol reagent (Invitrogen, USA), and $2 \mu \mathrm{g}$ was used for first-strand cDNA synthesis with the RevertAid ${ }^{\mathrm{TM}}$ First Strand cDNA Synthesis Kit (Fermentas, LTU). The primers for human VASP were 5'-AAAGTCAGCAAGCAGGAGGA-3' and 5'-ATTCATCCTTGGGGGTTTTC-3'. The primer set was amplified with increasing numbers of cycles of $95^{\circ} \mathrm{C}$ for $15 \mathrm{~s}, 58^{\circ} \mathrm{C}$ for $15 \mathrm{~s}, 72^{\circ} \mathrm{C}$ for $45 \mathrm{~s}$ and a final extension of $72^{\circ} \mathrm{C}$ for $5 \mathrm{~min}$. The primers for $\beta$-actin were $5^{\prime}$-GTCCACCGCAAATGCTTCTA-3' and 5'-TGCTGTCACCTTCACCGTTC-3'. The semi-quantitative PCR was performed with the iCycler iQ Real Time PCR Detection System (Bio-Rad Laboratories, Inc, Hercules, CA, USA) in the presence of SYBR Green. All PCR reactions were run in triplicate and were repeated at least three times. The differences were calculated according to the $\Delta \Delta \mathrm{Ct}$ relative quantization method; the $\beta$-actin gene was used for calibration.

\section{Western blotting analysis}

To identify the effects of matrine on the cellular expression levels of VASP protein, serum-starved cells were treated with matrine $(0,50$, and $100 \mu \mathrm{g} / \mathrm{mL})$ for $24 \mathrm{~h}$. Cells were lysed directly in lysis buffer [1\% Triton X-100, $50 \mathrm{mmol} / \mathrm{L}$ Tris- $\mathrm{HCl}$ (pH 7.4), $25 \mathrm{mmol} / \mathrm{L}$ glycerophosphate, $150 \mathrm{mmol} / \mathrm{L} \mathrm{NaCl}$, $2 \mathrm{mmol} / \mathrm{L}$ EDTA, $2 \mathrm{mmol} / \mathrm{L}$ EGTA, $1 \mathrm{mmol} / \mathrm{L} \mathrm{PMSF}, 10 \%$ glycerol, protease and phosphatase inhibitors] for $10 \mathrm{~min}$ on ice. The lysates were scraped into microcentrifuge tubes and centrifuged at $14000 \mathrm{r} / \mathrm{min}$ for $15 \mathrm{~min}$ at $4^{\circ} \mathrm{C}$. The supernatants were quantified with a BCA kit and equal amounts of 
protein were added to each lane of a 10\% SDS-polyacrylamide gel. The proteins were separated by electrophoresis and transferred to polyvinyldifluoride (PVDF) membranes. The membranes were incubated with anti-total VASP (VASP-IE273, Alexis) and anti-phospho-VASP (Ser157; Santa Cruz Biotechnology, TX, USA) antibodies. Next, the membranes were washed with Tris-buffered saline with Tween 20 (TBST) and incubated with an alkaline phosphatase-conjugated secondary antibody (Promega Corp, WI, USA). The proteins were visualized by chromatogenous substrate reactions. The $\beta$-actin antibody was used as a loading control.

\section{Statistical analysis}

All results are presented as the mean \pm SEM. Statistical analyses of the data with equal variances were carried out by oneway or two-way analysis of variance (ANOVA), followed by Tukey's post hoc test where appropriate. A value of $P<0.01$ was considered very significant. A value of $P<0.05$ was considered statistically significant.

\section{Results}

\section{Matrine affects the secondary structure of VASP}

VASP is known to regulate actin filament assembly and gathering and thereby to participate in various cell behaviors related to the actin cytoskeleton, such as adhesion, contraction and motility ${ }^{[22-25]}$. To study the direct effect of matrine on VASP, the expression plasmid pET28a-VASP, which encodes the full-length human VASP, was constructed. The SDS-PAGE gel results that are shown in Figure 2A indicate that both the supernatant and the precipitate contained the VASP protein. The purified proteins were eluted primarily with $500 \mathrm{mmol} / \mathrm{L}$ imidazole, and ultrafiltration was used to concentrate the proteins and replace the buffer. Only one bright electrophoretic band that corresponded to the collected fraction was observed, indicating that VASP was purified successfully.

To confirm the correct expression of VASP, the recombinant VASP was verified by Western blot analysis. As shown in Figure 2B, the collected fraction contained VASP as well as a small amount of $\mathrm{p}$-VASP (Ser157).
A
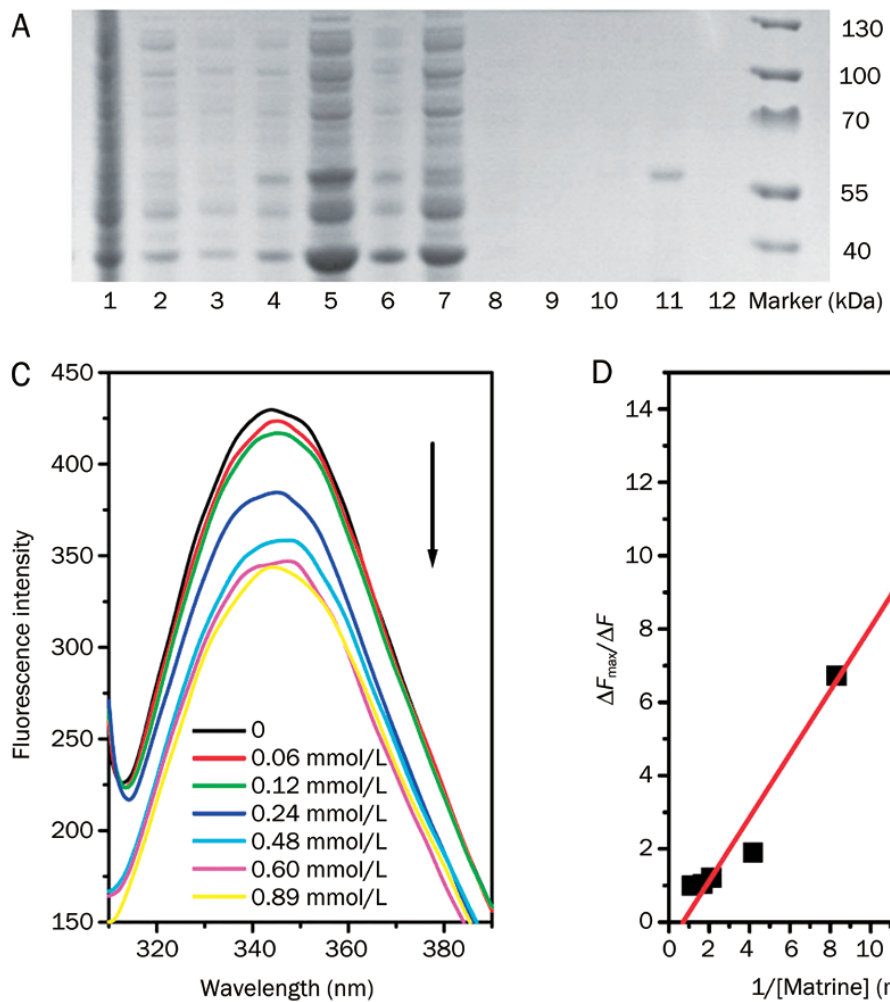

D

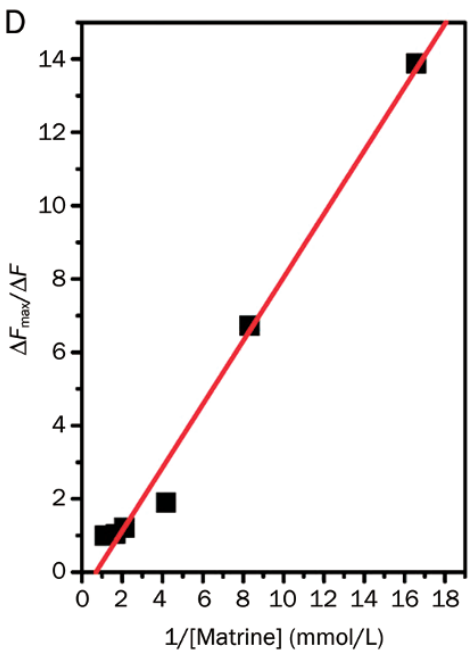

B

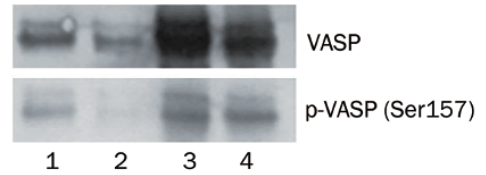

E

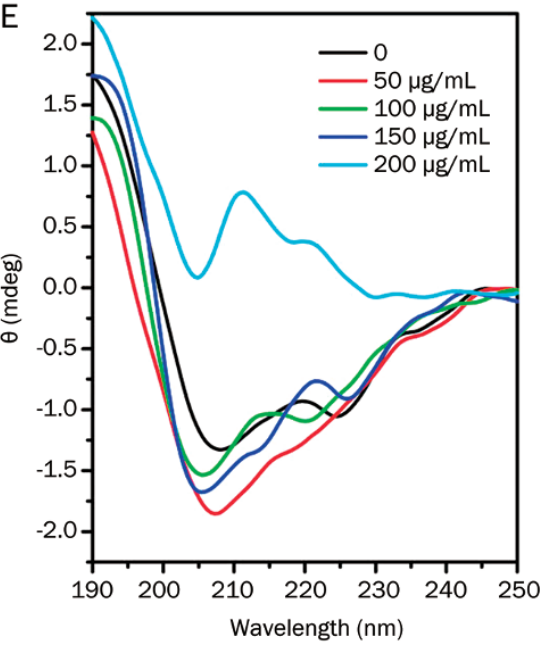

Figure 2. Matrine affected the VASP secondary structure. Human VASP was expressed, purified and measured by SDS-PAGE, Western blotting analysis, intrinsic fluorescence spectroscopy and circular dichroism spectroscopy. (A) SDS-PAGE analysis of VASP expression. Lane 1, pET-28a before IPTG induction; lane 2, pET-28a after IPTG induction for $16 \mathrm{~h}$ at $18^{\circ} \mathrm{C}$; lane 3, pET-28a-VASP before IPTG induction; lane 4, pET-28a-VASP after IPTG induction for $16 \mathrm{~h}$ at $18{ }^{\circ} \mathrm{C}$; lane 5, supernatant; lane 6 , precipitate; lane 7, lysate; lane 8, wash buffer with 20 mmol/L imidazole; lane 9 , wash buffer with $50 \mathrm{mmol} / \mathrm{L}$ imidazole; lane 10, elution buffer with $500 \mathrm{mmol} / \mathrm{L}$ imidazole; lane 11, fraction collected by ultrafiltration; and lane 12 , remainder of ultrafiltration. (B) Western blotting of VASP expression. Lane 1, wash buffer with $20 \mathrm{mmol} / \mathrm{L}$ imidazole; lane 2, wash buffer with $50 \mathrm{mmol} / \mathrm{L}$ imidazole; lane 3, elution buffer with $500 \mathrm{mmol} / \mathrm{L}$ imidazole; lane 4, fraction collected by ultrafiltration. (C) Intrinsic fluorescence spectra of VASP in the presence of different concentrations of matrine at $25.0^{\circ} \mathrm{C}$. (D) The dissociation constant was obtained from the fluorescence assay by linear fitting. (E) The farUV CD spectra that corresponded to the VASP secondary structure were sensitive to the concentration of matrine. 
The purpose of expressing and purifying VASP was to study its structure. Tryptophan is a useful intrinsic probe because its emission fluorescence spectrum varies with the molecular environment of the side chain; disruption of the native protein structure leads to changes in the exposure of the tryptophan side chains to the solvent. Herein, the fluorescence emission spectra of the tryptophan residues in VASP were monitored following excitation at $295 \mathrm{~nm}$. As shown in Figure 2C, when the concentration of matrine increased from 0 to $0.89 \mathrm{mmol} / \mathrm{L}$, the fluorescence intensity of VASP decreased with no significant shift of the maximum fluorescence emission wavelength. A plot of the fluorescence intensity $v s$ matrine concentration was approximately linear in this range (Figure 2D). The dissociation constant derived from the binding curve was 0.86 $\mathrm{mmol} / \mathrm{L}$, which indicated that the direct binding between matrine and the VASP protein was weak. Figure 2E shows the far-UV CD spectra of VASP with different concentrations of matrine at $25.0^{\circ} \mathrm{C}$. The far-UV CD spectrum of VASP in the absence of matrine exhibited two additional intense negative maxima at 222 and $208 \mathrm{~nm}$, suggesting a significant presence of $a$-helical structure. At a matrine concentration of $50 \mu \mathrm{g} / \mathrm{mL}$, the intense negative maximum at $222 \mathrm{~nm}$ was no longer apparent. However, a partial recovery of the two negative maxima was observed when the concentration of matrine was increased to $100-150 \mu \mathrm{g} / \mathrm{mL}$. There was a significant loss of the far-UV CD signal at a matrine concentration of 200 $\mu \mathrm{g} / \mathrm{mL}$. Collectively, these results indicate that matrine can alter the secondary structure of VASP to some extent and that the secondary protein structure of VASP was most sensitive to
$50 \mu \mathrm{g} / \mathrm{mL}$ of matrine.

\section{Matrine inhibited BGC823 cell migration and adhesion}

To study the effect of matrine on human gastric cancer cell migration, we analyzed the migratory behavior of BGC823 cells in a wound-healing assay. As shown in Figure 3A, significant cell migration was observed at the wound margin of the control group (no matrine) after $24 \mathrm{~h}$. However, wound healing was not clearly observed in cells that were treated with matrine (50 and $100 \mu \mathrm{g} / \mathrm{mL}$ ) for $24 \mathrm{~h}$. Cell migration at the wound margins was markedly inhibited after $24 \mathrm{~h}$ of matrine treatment. The statistical data $($ mean $\pm S D)$ shown in Figure 3B were obtained from four independent experiments. The percentage of wound closure was $28.7 \pm 3.5$ in the control, and was significantly reduced in the cells treated with 50 and $100 \mu \mathrm{g} / \mathrm{mL}$ matrine $(8.4 \pm 2.5$ and $10.3 \pm 2.4$, respectively, $n=4$, $P<0.01)$.

The effect of matrine on the adhesion ratio of human gastric cancer cells was quantified with an MTT assay. Statistical data that corresponded to both Fn (Figure 3C) and Matrigel (Figure 3D) were obtained from four independent experiments (mean $\pm \mathrm{SD}$ ). For cells that were treated with $50 \mu \mathrm{g} / \mathrm{mL}$ of matrine for $24 \mathrm{~h}$, the cell adhesion ratio was significantly reduced with Fn and with Matrigel $(P<0.01, P<0.05)$ relative to that of the control, which was arbitrarily set at 1 for each experiment. For cells that were treated with $100 \mu \mathrm{g} / \mathrm{mL}$ of matrine for $24 \mathrm{~h}$, the cell adhesion ratio was significantly reduced with Fn $(P<0.05)$ but not with Matrigel $(P>0.05)$ relative to that of the control. These data indicate that cell
A

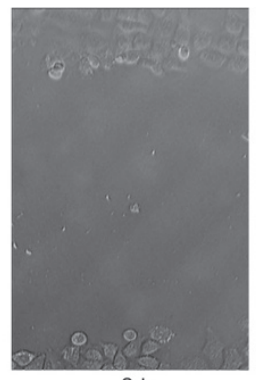

$\mathrm{Oh}$

0 matrine

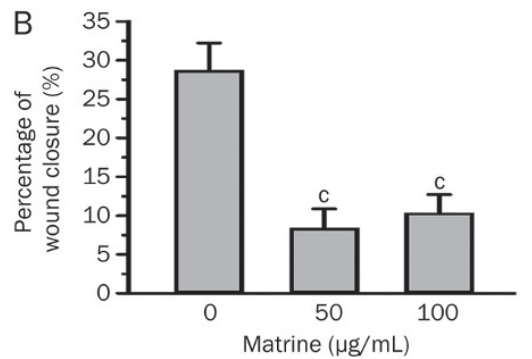

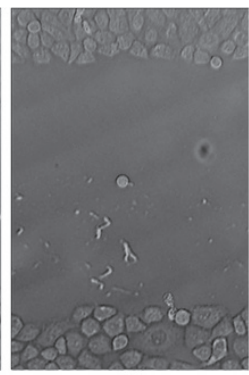

$\mathrm{Oh}$

$50 \mu \mathrm{g} / \mathrm{mL}$ matrine

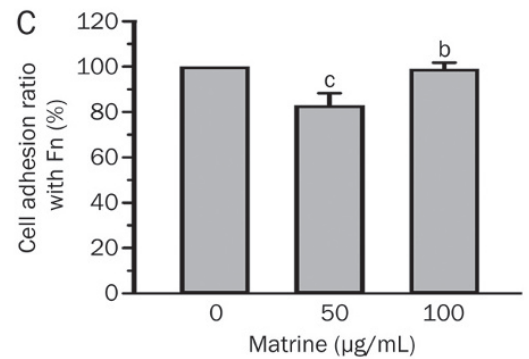

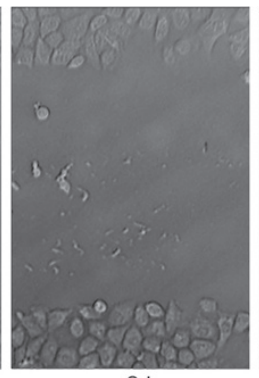

$\mathrm{Oh}$

$100 \mu \mathrm{g} / \mathrm{mL}$ matrine

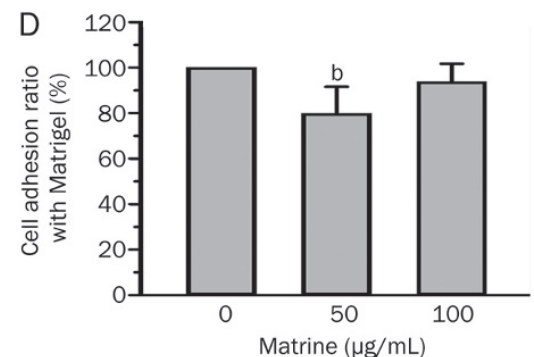

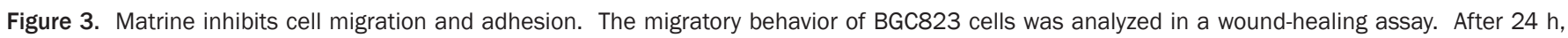

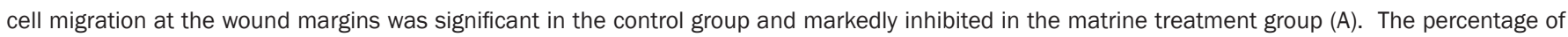

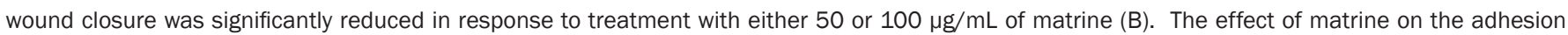

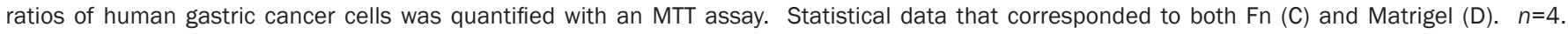
Mean \pm SEM. ${ }^{b} P<0.05,{ }^{c} P<0.01$ vs the control value. 
adhesion to Fn or Matrigel was more sensitive to $50 \mu \mathrm{g} / \mathrm{mL}$ of matrine. All the data that contributed to the final analysis shown in Figures 3C and 3D are presented in Tables 1 and 2.

Table 1. Values for the cell adhesion ratio with fibronectin were quantified using the MTT assay and then calculated by comparing 50 or $100 \mu \mathrm{g} / \mathrm{mL}$ matrine-treated samples with control samples, which were arbitrarily set at 1 for each experiment. ${ }^{b} P<0.05,{ }^{c} P<0.01$ compared with control value.

\begin{tabular}{lll}
\hline Matrine & $50 \mu \mathrm{g} / \mathrm{mL}$ & $100 \mu \mathrm{g} / \mathrm{mL}$ \\
\hline Fibronectin & $82.8 \pm 5.5^{\mathrm{c}}$ & $92.3 \pm 2.8^{\mathrm{b}}$ \\
Matrigel & $79.9 \pm 11.7^{\mathrm{c}}$ & $93.9 \pm 7.8^{\mathrm{b}}$ \\
\hline
\end{tabular}

Table 2. Values for the percent change in p-VASP (Ser157) and VASP expression were calculated by comparing 50 and $100 \mu \mathrm{g} / \mathrm{mL}$ matrine or $1.0 \mu \mathrm{g} / \mathrm{mL}$ PMA-stimulated samples to untreated samples, which were arbitrarily set at $100 \%$ for each experiment. $n=4 .{ }^{b} P<0.05,{ }^{c} P<0.01$ compared with the control value.

\begin{tabular}{lccc}
\hline & $\begin{array}{c}\text { Matrine } \\
50 \mu \mathrm{g} / \mathrm{mL}\end{array}$ & $\begin{array}{c}\text { Matrine } \\
100 \mu \mathrm{g} / \mathrm{mL}\end{array}$ & $\begin{array}{c}\text { PMA } \\
1.0 \mu \mathrm{m} / \mathrm{mL}\end{array}$ \\
\hline p-VASP (Ser157) & $\begin{array}{l}59.8 \pm 1.8^{\mathrm{c}} \\
70.8 \pm 9.4^{\mathrm{b}}\end{array}$ & $\begin{array}{c}69.1 \pm 2.6^{\mathrm{c}} \\
66.1 \pm 8.8^{\mathrm{b}}\end{array}$ & $\begin{array}{c}320.9 \pm 30.2 \\
125.0 \pm 20.5\end{array}$ \\
\hline
\end{tabular}

Matrine affected the subcellular distribution of VASP and the formation of actin stress fibers

The impacts of matrine on the subcellular distribution of VASP and F-actin were identified to further investigate how matrine inhibits cell migration and adhesion. In the control group, the concentration of F-actin was observed to be higher in the nucleus than in the cytoplasm. Additionally, the stress fibers gathered by F-actin were arranged predominantly in one direction. VASP was evenly distributed throughout the cell with no difference in concentration between the nucleus and cytoplasm. After treatment with $50 \mu \mathrm{g} / \mathrm{mL}$ of matrine, VASP was mainly distributed in the cytoplasm and the concentration of VASP was low in the nucleus. In the cell periphery, some irregular actin filaments were observed in the absence of stress fibers (Figure 4).

\section{Matrine inhibited both the expression and the phosphorylation of VASP}

To further clarify the effects of matrine on VASP in BGC823 cells, the role of matrine on the transcription and expression levels of VASP was investigated. As shown in Figure 5, 50 and $100 \mu \mathrm{g} / \mathrm{mL}$ of matrine had no significant influence on the level of VASP mRNA expression in BGC823 cells when compared with the untreated group.

In Figure 6A, the band corresponding to $46 \mathrm{kDa}$ is shown to be significantly reduced after matrine treatment, relative to the untreated group. The band that corresponded to $50 \mathrm{kDa}$ in the control group was light in comparison to the same band in the PMA group. No obvious band was observed at $50 \mathrm{kDa}$ in the matrine-treated groups. The values for the percent change in p-VASP (Ser157) and VASP expression were calculated by comparing the 50 or $100 \mu \mathrm{g} / \mathrm{mL}$ matrine or the $1.0 \mu \mathrm{g} / \mathrm{mL}$ PMA-stimulated samples to the untreated samples, which were arbitrarily set at $100 \%$ for each experiment. After the cells were treated with 50 or $100 \mu \mathrm{g} / \mathrm{mL}$ of matrine for $24 \mathrm{~h}$, the expression levels of p-VASP (Ser157) were significantly reduced relative to those of the untreated group $(P<0.01)$. VASP expression was clearly reduced in response to 50 or 100 $\mu \mathrm{g} / \mathrm{mL}$ of matrine $(P<0.05)$. All the data that contributed to the final analysis shown in Figure 6B are presented in Table 2.

\section{Discussion}

Matrine, a natural compound, has been used as an anticancer herb in its long history due to its wide range of biological activities and low toxicity. Thus, it is necessary to explore
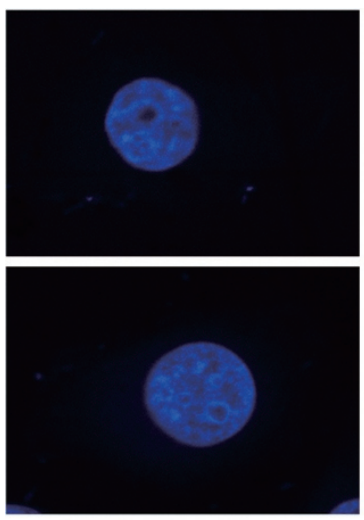

Cell nucleus
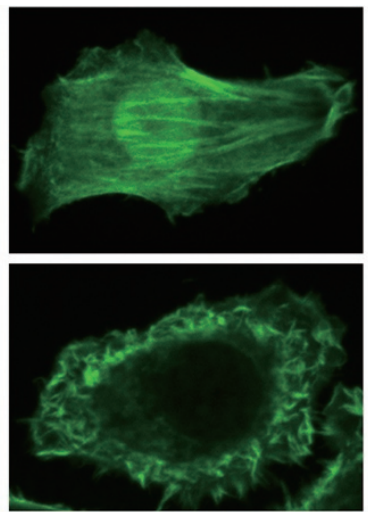

Actin
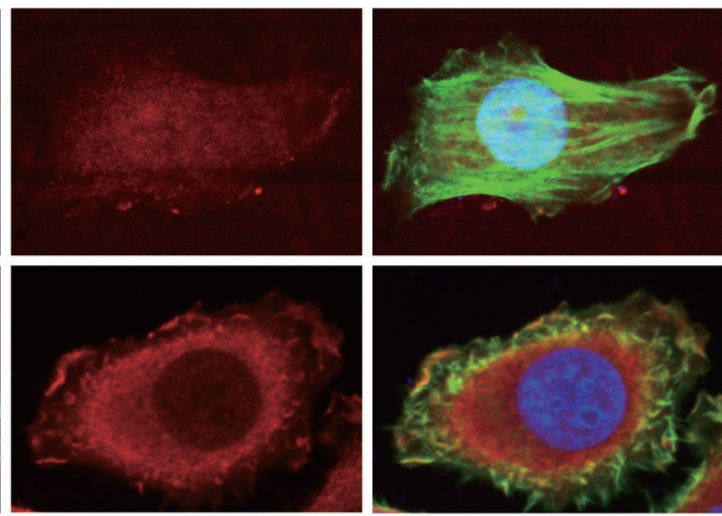

VASP

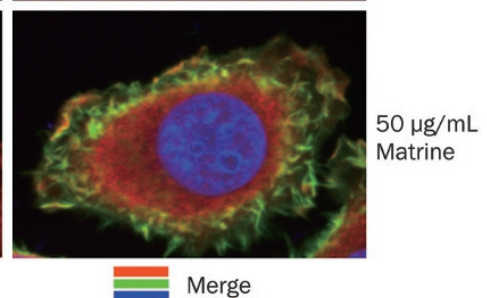

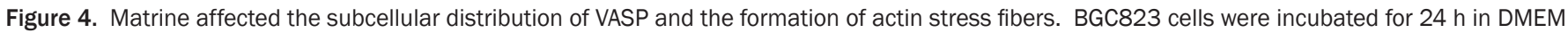

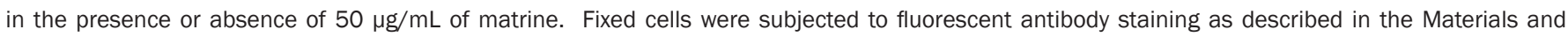
methods section. The fluorescent staining was visualized and photographed with a laser confocal scanning microscope. 


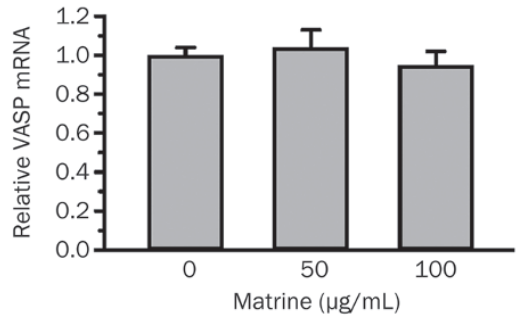

Figure 5. Matrine had no significant effects on the level of VASP mRNA expression in BGC823 cells. The effect of matrine on VASP transcript levels was identified by semi-quantitative real-time PCR. $n=3$. Mean \pm SEM.

A

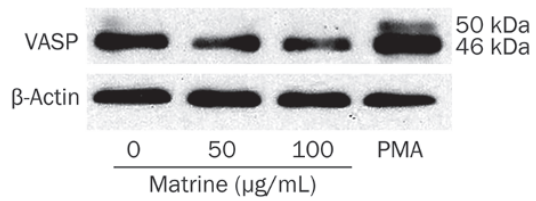

B

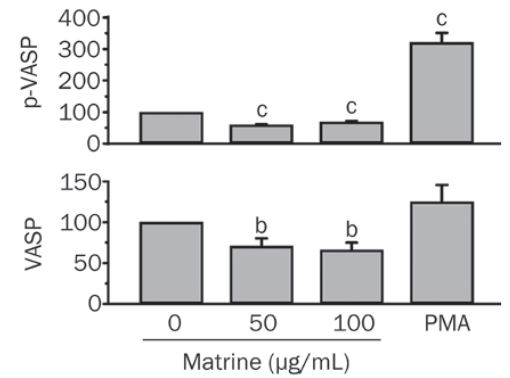

Figure 6. Matrine inhibited the phosphorylation of VASP. The effects of matrine on both the expression and the Ser157 phosphorylation levels of VASP were identified by Western blotting analysis (A). Values for the percent change in $\mathrm{p}$-VASP and VASP expression were calculated by comparing the 50 and $100 \mu \mathrm{g} / \mathrm{mL}$ matrine or $1.0 \mu \mathrm{g} / \mathrm{mL}$ PMA-stimulated samples to the untreated samples, which were arbitrarily set at $100 \%$ for each experiment. $n=3$. Mean \pm SEM. ${ }^{b} P<0.05,{ }^{c} P<0.01$ vs control value (B).

the molecular mechanisms by which matrine inhibits cancer cell adhesion, migration, and metastasis. The data presented in this study demonstrate that the direct binding between matrine and VASP is weak, that the most obvious change in the secondary structure of VASP was observed in response to a $50 \mu \mathrm{g} / \mathrm{mL}$ matrine treatment, that $50 \mu \mathrm{g} / \mathrm{mL}$ of matrine inhibited the migration and adhesion of human gastric cancer BGC 823 cells and that $50 \mu \mathrm{g} / \mathrm{mL}$ of matrine changed both the subcellular distribution of VASP and the formation of actin stress fibers in BGC 823 cells. Additionally, $50 \mu \mathrm{g} / \mathrm{mL}$ of matrine inhibited both the expression and the phosphorylation of VASP with no significant effects on the level of VASP mRNA expression in BCG823 cells.

VASP is an actin regulatory protein with functions in cell migration and adhesion. The reorganization of actin structures is fundamental in driving cell migration and adhesion. The actin regulatory functions of VASP are highly sensitive to salt concentrations, which suggests that the phosphorylation of VASP could dramatically affect the actin regulatory activity. Of the three VASP conservative phosphorylation sites (Ser-157, Ser-239, and Thr-278), only the phosphorylation of Ser-157 led to a shift in the apparent molecular mass from 46 to $50 \mathrm{kDa}$, indicating that this phosphorylation might cause a change in the secondary structure of the molecule ${ }^{[26,27]}$. Our data showed that the far-UV CD spectra that corresponded to the VASP secondary structure were sensitive to the concentration of matrine. In the absence of matrine, VASP had a significant amount of a-helical structure that was reduced when the matrine concentration reached $50 \mu \mathrm{g} / \mathrm{mL}$ and was partially recovered when the matrine concentration was increased to $100-150 \mu \mathrm{g} / \mathrm{mL}$. There was a significant loss of the VASP secondary structure when the matrine concentration reached $200 \mu \mathrm{g} / \mathrm{mL}$. The phosphorylation of VASP at Ser157 was also significantly inhibited in BGC823 cells by treatment with 50 $\mu \mathrm{g} / \mathrm{mL}$ of matrine, demonstrating that matrine could affect the structure and function of VASP through the inhibition of VASP phosphorylation in these cells. These findings agree with previous reports describing the effects of matrine on other types of cancer cells ${ }^{[6,8,18,28,29]}$.

Ena/VASP proteins display a conserved tripartite architecture that encompasses an N-terminal Ena/VASP homology 1 (EVH1) domain that is required for subcellular targeting, a central proline-rich domain that is implicated in the recruitment of profilin-actin complexes, and a C-terminal EVH2 domain that mediates tetramerization and interaction with globular $(\mathrm{G})$ and filament $(\mathrm{F})$ actins $^{[28,29]}$. VASP contains G-actin, profilin, and F-actin binding sites that allow VASP to act as an actin-barbed, end-binding protein and facilitates actin filament elongation. Studies of fibroblasts have shown that Ena/ VASP depletion leads to shorter actin filaments at the leading edge, relative to controls. Conversely, Ena/VASP overexpression leads to longer than normal filaments at the leading edge. VASP also facilitates actin filament bundling and may antagonize the formation of Arp2/3 complexes during the formation of branched actin networks. The association of Ena/ VASP proteins with actin filaments might either compete with Arp2/3 for binding sites near the barbed end or condition the filaments to inhibit branching or to promote debranching. Our immunofluorescence assay results demonstrated that treatment with $50 \mu \mathrm{g} / \mathrm{mL}$ of matrine changed both the subcellular distribution of VASP and the formation of actin stress fibers in human gastric cancer cells. Both actin stress fiber formation and cell migration correspond to VASP function. These observations further indicated that matrine could change the function of VASP in BGC823 cells at the same concentration that affected the secondary protein structure of VASP. Additionally, this might explain why matrine did not affect cancer cells in a dose-dependent manner, according to Ma et al ${ }^{[6]}$.

VASP is highly expressed in vascular endothelial and smooth muscle cells, where it contributes to the stabilization of endothelial cell-cell contacts and improves vascular barrier functions. VASP expression is upregulated during vasculogenesis and angiogenesis. Several studies have reported that 
VASP expression levels are associated with tumorigenesis in vitro and in vivo. Dertsiz et al reported that VASP might be involved in lung adenocarcinoma proliferation through the regulation of intracellular F-actin formation, focal adhesion, and cell migration. The phosphorylation of VASP was thought to play an important role in cancer invasion and metastasis. Alterations in the regulatory reorganization of actin and decrease in migration and strength of cell-cell adhesion were observed in response to perturbations of VASP function $^{[30]}$. Zhang et al found that matrine might inhibit HeLa cell adhesion and migration by decreasing the phosphorylation of VASP via the inhibition of PKA activity ${ }^{[8]}$. Our results from the two-dimensional cell migration assay and the cell adhesion assay demonstrated that treatment with $50 \mu \mathrm{g} / \mathrm{mL}$ of matrine could inhibit the migration and adhesion of BGC823 cells. Interestingly, the semi-quantitative real-time results revealed that matrine did not significantly affect the level of VASP mRNA expression in BGC823 cells; however, Western blot analysis clearly illustrated decreases in both the expression and phosphorylation of VASP in response to treatments with 50 or $100 \mu \mathrm{g} / \mathrm{mL}$ of matrine, indicating that matrine might induce the degradation of VASP protein at these concentrations through effects on the VASP secondary structure. However, this mechanism must be studied further.

In summary, we have revealed that the structure of VASP was sensitive to treatment with $50 \mu \mathrm{g} / \mathrm{mL}$ of matrine in both an aqueous solution and BGC823 cells. VASP functions, such as the promotion of actin stress fiber formation and cell migration, were also significantly inhibited by treatment with 50 $\mu \mathrm{g} / \mathrm{mL}$ of matrine in BGC823 cells. Interestingly, the VASP secondary protein structure is sensitive to the concentration of matrine, and this finding might represent a novel mechanism by which specific doses of matrine selectively affect tumor cells.

\section{Abbreviations}

VASP, vasodilator-stimulated phosphoprotein; G-actin, globular actin; F-actin, filamentous actin; DMEM, Dulbecco's modified Eagle's medium; FBS, fetal bovine serum; Fn, fibronectin; MTT, 3-(4,5-dimethyl-2-thiazolyl)-2,5-diphenyltetrazolium bromide; DMSO, dimethylsulfoxide; $O D$, optical density; PVDF, polyvinyldifluoride; TBST, Tris-buffered saline with Tween 20; IPTG, isopropyl-1-thio- $\beta$ - $D$-galactopyranoside; CD, circular dichroism.

\section{Acknowledgements}

This work was supported by grants from the National Natural Science Foundation of China (№ 30900122, 30971132, and 31170328).

\section{Author contribution}

Fang YANG and Jin XIANG designed research; Jing-wei ZHANG, Ke SU and Wen-tao SHI performed research; Ying WANG and Peng-chao HU contributed new analytical tools and reagents; Yang WANG and Lei WEI analyzed data; Fang YANG and Jin XIANG wrote the paper.

\section{References}

1 Li X, Chu W, Liu J, Xue X, Lu Y, Shan H, et al. Antiarrhythmic properties of long-term treatment with matrine in arrhythmic rat induced by coronary ligation. Biol Pharm Bull 2009; 32: 1521-6.

2 Liu XY, Fang H, Yang ZG, Wang XY, Ruan LM, Fang DR, et al. Matrine inhibits invasiveness and metastasis of human malignant melanoma cell line A375 in vitro. Int J Dermatol 2008; 47: 448-56.

3 Long Y, Lin XT, Zeng KL, Zhang L. Efficacy of intramuscular matrine in the treatment of chronic hepatitis B. Hepatobiliary Pancreat Dis Int 2004; 3: 69-72.

4 Brenner H, Rothenbacher D, Arndt V. Epidemiology of stomach cancer. Methods Mol Biol 2009; 472: 467-77.

5 Liu T, Song Y, Chen H, Pan S, Sun X. Matrine inhibits proliferation and induces apoptosis of pancreatic cancer cells in vitro and in vivo. Biol Pharm Bull 2010; 33: 1740-5.

6 Ma L, Wen S, Zhan Y, He Y, Liu X, Jiang J. Anticancer effects of the Chinese medicine matrine on murine hepatocellular carcinoma cells. Planta Med 2008; 74: 245-51.

7 Zhang LP, Jiang JK, Tam JW, Zhang Y, Liu XS, Xu XR, et al. Effects of matrine on proliferation and differentiation in K-562 cells. Leuk Res 2001; 25: 793-800.

8 Zhang L, Wang T, Wen X, Wei Y, Peng X, Li H, et al. Effect of matrine on HeLa cell adhesion and migration. Eur J Pharmacol 2007; 563: 69-76.

9 Bear JE, Svitkina TM, Krause M, Schafer DA, Loureiro JJ, Strasser GA, et al. Antagonism between Ena/VASP proteins and actin filament capping regulates fibroblast motility. Cell 2002; 109: 509-21.

10 Schirenbeck A, Arasada R, Bretschneider T, Stradal TE, Schleicher M, Faix J. The bundling activity of vasodilator-stimulated phosphoprotein is required for filopodium formation. Proc Natl Acad Sci U S A 2006; 103: 7694-9.

11 Han G, Fan B, Zhang Y, Zhou X, Wang Y, Dong H, et al. Positive regulation of migration and invasion by vasodilator-stimulated phosphoprotein via Rac1 pathway in human breast cancer cells. Oncol Rep 2008; 20: 929-39.

$12 \mathrm{Hu}$ LD, Zou HF, Zhan SX, Cao KM. EVL (Ena/VASP-like) expression is up-regulated in human breast cancer and its relative expression level is correlated with clinical stages. Oncol Rep 2008; 19: 1015-20.

13 Kwei KA, Finch JS, Ranger-Moore J, Bowden GT. The role of Rac1 in maintaining malignant phenotype of mouse skin tumor cells. Cancer Lett 2006; 231: 326-38.

14 Philippar U, Roussos ET, Oser M, Yamaguchi H, Kim HD, Giampieri S, et al. A Mena invasion isoform potentiates EGF-induced carcinoma cell invasion and metastasis. Dev Cell 2008; 15: 813-28.

15 Quinlan MP. Suppression of epithelial cell transformation and induction of actin dependent differentiation by dominant negative Rac1, but not Ras, Rho or Cdc42. Cancer Biol Ther 2004; 3: 65-70.

16 Jiang $\mathrm{H}$, Hou $\mathrm{C}$, Zhang $\mathrm{S}$, Xie $\mathrm{H}$, Zhou W, Jin Q, et al. Matrine upregulates the cell cycle protein E2F-1 and triggers apoptosis via the mitochondrial pathway in K562 cells. Eur J Pharmacol 2007; 559: 98-108.

17 Yu P, Liu Q, Liu K, Yagasaki K, Wu E, Zhang G. Matrine suppresses breast cancer cell proliferation and invasion via VEGF-Akt-NF-kappaB signaling. Cytotechnology 2009; 59: 219-29.

18 Zhang Y, Zhang H, Yu P, Liu Q, Liu K, Duan H, et al. Effects of matrine against the growth of human lung cancer and hepatoma cells as well as lung cancer cell migration. Cytotechnology 2009; 59: 191-200.

19 Hansen SD, Mullins RD. VASP is a processive actin polymerase that requires monomeric actin for barbed end association. J Cell Biol 2010; 191: 571-84.

20 Xiang J, Yu CP, Yang F, Yang L, Ding H. Conformation-activity studies 
on the interaction of berberine with acetylcholinesterase: Physical chemistry approach. Prog Nat Sci 2009; 19: 1721-5.

21 Xiang J, Fan JB, Chen N, Chen J, Liang Y. Interaction of cellulase with sodium dodecyl sulfate at critical micelle concentration level. Colloids Surf B Biointerfaces 2006; 49: 175-80.

22 Bachmann C, Fischer L, Walter U, Reinhard M. The EVH2 domain of the vasodilator-stimulated phosphoprotein mediates tetramerization, F-actin binding, and actin bundle formation. J Biol Chem 1999; 274: 23549-57.

23 Chereau D, Dominguez R. Understanding the role of the G-actinbinding domain of Ena/VASP in actin assembly. J Struct Biol 2006; 155: 195-201.

24 Walders-Harbeck B, Khaitlina SY, Hinssen H, Jockusch BM, Illenberger $\mathrm{S}$. The vasodilator-stimulated phosphoprotein promotes actin polymerisation through direct binding to monomeric actin. FEBS Lett 2002; 529: 275-80.

25 Zhang Y, Han G, Fan B, Zhou Y, Zhou X, Wei L, et al. Green tea (-)-epigallocatechin-3-gallate down-regulates VASP expression and inhibits breast cancer cell migration and invasion by attenuating Rac1 activity. Eur J Pharmacol 2009; 606: 172-9.

26 Lee S, Chung CY. Role of VASP phosphorylation for the regulation of microglia chemotaxis via the regulation of focal adhesion formation/ maturation. Mol Cell Neurosci 2009; 42: 382-90.

27 Lin WH, Nelson SE, Hollingsworth RJ, Chung CY. Functional roles of VASP phosphorylation in the regulation of chemotaxis and osmotic stress response. Cytoskeleton (Hoboken) 2010; 67: 259-71.

28 Breitsprecher D, Kiesewetter AK, Linkner J, Urbanke C, Resch GP, Small JV, et al. Clustering of VASP actively drives processive, WH2 domain-mediated actin filament elongation. EMBO J 2008; 27 : 2943-54.

29 Ferron F, Rebowski G, Lee SH, Dominguez R. Structural basis for the recruitment of profilin-actin complexes during filament elongation by Ena/VASP. EMBO J 2007; 26: 4597-606.

30 Dertsiz L, Ozbilim G, Kayisli Y, Gokhan GA, Demircan A, Kayisli UA. Differential expression of VASP in normal lung tissue and lung adenocarcinomas. Thorax 2005; 60: 576-81. 